\title{
A NOTE ON $\delta$-QUASI-MONOTONE AND ALMOST INCREASING SEQUENCES
}

\author{
H. BOR AND L. LEINDLER
}

Abstract. In this paper by using an almost increasing sequence a general theorem on $\varphi-$ $|C, \alpha|_{k}$ summability factors, which among others generalizes a result of Mazhar[9] on $|C, 1|_{k}$ summability factors, has been proved under weaker conditions.

Mathematics subject classification (2000): 40D15, 40F05, 40G05.

Key words and phrases: absolute summability, almost increasing and quasi-monotone sequences.

\section{REFERENCES}

[1] S. Aljancic And D. ARAndelovic, O -regularly varying functions, Publ. Inst. Math., 22 (1977), 5-22.

[2] M. BALCI, Absolute $\varphi$-summability factors, Comm. Fac. Sci. Univ. Ankara, Ser. $A_{1} 29$ (1980), 63-80.

[3] R. P. BoAs, Quasi-positive sequences and trigonometric series, Proc. London Math. Soc. Ser. A 14 (1965), 38-46.

[4] L. S. BosAnQuet, A mean value theorem, J. London Math. Soc., 16 (1941), 146-148.

[5] T. M. FLETT, On an extension of absolute summability and some theorems of Littlewood and Paley, Proc. London Math. Soc., 7 (1957), 113-141.

[6] T. M. FLETT, Some more theorems concerning the absolute summability of Fourier series, Proc. London Math. Soc., 8 (1958), 357-387.

[7] L. LEINDLER, On extensions of some theorems of Flett. I, Acta Math. Hungar., 64 (3) (1994), 269-283.

[8] L. LEINDLER, Three theorems connected with $\delta$-quasi monotone sequences and their applications to an integrability theorem, Publ. Math. (Debrecen), 60 (2002), 373-384.

[9] S. M. MAZHAR, On a generalized quasi-convex sequence and its applications, Indian J. Pure Appl. Math., 8 (1977), 784-790.

[10] T. PATI, The summability factors of infinite series, Duke Math. J. 21 (1954), 271-284. 